\title{
Comparing the configured causal antecedents of exploration and exploitation: a fuzzy set qualitative comparative analysis
}

\author{
Lulu Liu', Fengbin Wang ${ }^{1 *}$ (D) and Xiukun Li
}

\author{
* Correspondence: \\ rbs_wangfengbin@163.com \\ ${ }^{1}$ Renmin Business School, Renmin \\ University of China, Beijing 100872, \\ China \\ Full list of author information is \\ available at the end of the article
}

\begin{abstract}
Although exploration and exploitation, as a pair of paradoxical organizational outcomes, are generated by different causal conditions, the conjunction of their respective causal antecedents has yet to be fully examined. Combining environmental uncertainty, unit interdependence, entrepreneurial bricolage and firm life cycle stage in a qualitative comparative analysis (QCA), the distinct causal configurations of exploration and exploitation are formalized and compared based on a survey of founders or high-level managers in 63 small firms. Results show that contrasted relationships between entrepreneurial bricolage and unit interdependence exist in that the two antecedents are partial substitutes in exploration whereas they are complements in exploitation when combined with other conditions. This study provides empirical evidence on the causal configurations of exploration and exploitation and deepens our current understanding of ambidexterity.
\end{abstract}

Keywords: Exploration, Exploitation, Ambidexterity, Configuration, Qualitative comparative analysis (QCA), Environmental uncertainty, Entrepreneurial bricolage, Unit interdependence

\section{Introduction}

Since March (1991) proposed balancing exploration and exploitation in organizational learning, the twin concepts have received much attention in the field of organization and management. In practicing paradoxical management, firms are increasingly inclined to pursue both kinds of activities even though there are trade-offs (Cao et al. 2009). Thus, “ambidexterity" - an organization's ability to both exploit mature technologies and markets that emphasize on efficiency, control and incremental innovations and explore new technologies and markets where flexibility, autonomy and experimentation are stressed (O'Reilly and Tushman 2013) - has been stressed by firms striving to balance short and long term performance (He and Wong 2004; Hoang and Rothaermel 2010; Jansen et al. 2006; Stettner and Lavie 2015).

The current literature explores a number of antecedents of ambidexterity, including organizational structures, behavioral contexts, leadership processes and environmental factors (Raisch and Birkinshaw 2008). Recently, Asif (2017) developed a taxonomy of

(c) The Author(s). 2019 Open Access This article is distributed under the terms of the Creative Commons Attribution 4.0 International License (http://creativecommons.org/licenses/by/4.0/), which permits unrestricted use, distribution, and reproduction in any medium, provided you give appropriate credit to the original author(s) and the source, provide a link to the Creative Commons license, and indicate if changes were made. 
ambidexterity antecedents: (1) infrastructural elements, such as organizational structures, processes, and context, and (2) organizational, group, and individual level antecedents. There is abundant literature on the antecedents of ambidexterity which often treats ambidexterity as a unifying construct (Asif 2017; Heavey and Simsek 2017; Raisch and Birkinshaw 2008; Turner et al. 2013), but seldom considers exploration and exploitation as two stand-alone dimensions of organizational learning, let alone simultaneously investigates and compares their distinct antecedents. However, for the kind of paradox reflected in the holistic, dynamic, and duality logic of "either/both" (Li 2012), the unity-in-contradiction implies the co-existence of separate aspects that are mutually contradictory as well as interrelated (Smith and Lewis 2011), thus raising the concern of whether the same antecedents of ambidexterity may work differently for exploration and exploitation.

The paradoxical perspective (Andriopoulos and Lewis 2009; Koryak et al. 2018; Lavie et al. 2010; Raisch and Zimmermann 2017) has cultivated an emerging stream of research into ambidexterity and implies theoretical and practical values to compare or contrast antecedents of exploration and exploitation. In particular, Smith (2014) provides a comprehensive framework to the inquiry of ambidexterity and distinguishes a differentiating approach from the currently highlighted integrative approach. Smith and Lewis (2011) argue that integration emphasizes the interrelated aspects of exploration and exploitation while differentiation concentrates on their contradictory aspects. Inferred from this comparison, the integration approach indicates the existence of some common or integrating antecedents that contribute to both exploration and exploitation whereas the differentiating approach indicates dissimilar or even contradicting antecedents of either exploration or exploitation (Koryak et al. 2018). Actually, Koryak and his colleagues (Koryak et al. 2018) find that top management team (TMT) heterogeneity and continuous improvement are integrating antecedents; in contrast, written vision, TMT size, R\&D intensity, and the product of TMT heterogeneity and size are differentiating antecedents.

The above advancement signifies the causal complexity in the explanation of different modes of organizational learning. The attempt to distinguish integrative antecedents from differentiating antecedents is meaningful to help firms balance exploration and exploitation and thus devise better strategies dealing with ambidexterity (Koryak et al. 2018). Building on this argument, we posit that there may not be absolute integrative antecedents and differentiating antecedents. In fact, from the neo-configurational perspective that embraces causal complexity, multiple antecedents combine together to achieve a given outcome, with individual antecedents playing a role through coupling with others in configurations (Misangyi et al. 2017). Consistent with this line of research and extending the work of Koryak and his colleagues, we regard the neo-configurational approach as the third approach to help reconcile the contradictions between exploration and exploitation in the process of attaining ambidexterity, that is, discovering combinations of different antecedents that constitute distinct paths for exploration and exploitation. Under this approach, the same antecedents can bring about exploration or exploitation or both, depending on how it couples with other antecedents. A single antecedent is neither integrative nor differentiating; instead, it functions as part of a specific configuration for exploration or exploitation. We call such antecedents configured 
causal antecedents. From this perspective, we contend that the paradoxical tensions are manageable when organizations design appropriate combinations of antecedents for exploration and exploitation to balance them.

Reflecting on the paradoxical perspective and neo-configurational thinking, in this study, we seek to answer one specific question: How do antecedents of exploration and/or exploitation combine to form various paths to exploration and exploitation in organizations? This combination effect is in accordance with Kauppila's (2010: p. 284) statement that "in reality, firms are likely to create ambidexterity through combining structural and contextual antecedents at both organizational and inter-organizational levels." To explore this question, we first identify two types of antecedents: environmental (e.g., environmental uncertainty) and organizational (e.g., organizational structure, entrepreneurial bricolage and life cycle stage) (Lavie et al. 2010). Then, based on survey data collected from the founders and high-level managers in 63 small-sized firms in China, we utilize an inductive, theory-elaborating approach-fuzzy set qualitative comparative analysis (fsQCA), a form of set-theoretic methodology (Fiss 2007) to investigate how these antecedents are combined as "casual recipes" (Ragin 2008) for exploratory or exploitative innovation. Finally, we analyze and compare the consequent equifinal paths (four paths for exploration and three paths for exploitation) and discuss their implications. Results indicate that each of the four antecedents is neither integrative nor differentiating, but can be expressed as "INUS" antecedents- that is, Insufficient but Necessary part of a condition which is itself Unnecessary but Sufficient for the result (Ragin 2014) - or configured causal antecedents. Further comparing different configurations of exploration and exploitation reveals that entrepreneurial bricolage and unit interdependence are partial substitutes in exploration whereas they are complements in exploitation.

By constructing causal configurations for exploration and exploitation, this paper contributes to the current literature in three aspects. First, this paper advances the understanding of ambidexterity. Previous research regards ambidexterity as a unifying construct and has thoroughly examined its antecedents, outcomes, and even moderators (Asif 2017; Heavey and Simsek 2017; Raisch and Birkinshaw 2008; Turner et al. 2013). However, from the paradoxical perspective, there are persistent tensions arising from the contradictory nature of exploration and exploitation and these tensions are difficult to resolve (Andriopoulos and Lewis 2009). Our work tries to reconcile these tensions by identifying the heterogeneous configurations of organizational and environmental antecedents towards exploration and exploitation. Organizations aimed at exploration or exploitation or both can pick their own "causal recipes" (Ragin 2008: p. 23). Second, entrepreneurial bricolage is added in our analysis. It is a relatively new concept proposed by Baker and Nelson (2005). By combining it with unit interdependence, we find underlying substitution and complementary effects between them, thus promoting the integration of the innovation and organizational structure literature. Third, our theoretical approach addresses the complex intersection of environmental and organizational factors. As the traditional statistic methods used in the majority of ambidexterity studies do not apply in this research, we thus make a methodological contribution to ambidexterity research by testing our conceptual model of causal complexity through the newly-applied method of QCA (Ragin 2008; Cronqvist 2005). 


\section{Theoretical framework}

\section{Exploration and exploitation as a paradox}

Smith and Lewis (2011: p. 386) denote paradox as "contradictory yet interrelated elements (dualities) that exist simultaneously and persist over time; such elements seem logical when considered in isolation but irrational, inconsistent, and even absurd when juxtaposed." Paradox resembles yin and yang dualities that are oppositional and contradictory to one another but are also synergistic and interrelated within a larger whole (Quinn and Cameron 1988). Exploration and exploitation illustrate the nature of paradox (Smith and Lewis 2011; Li 2012). As March (1991) describes, exploration and exploitation require conflicting strategies between search and refinement, risk taking and efficiency, as well as experimentation and choice. The paradoxical lens suggest that there are persistent tensions of exploration and exploitation as they require contradictory strategies, structures, organizational approaches and processes (Benner and Tushman 2003; Chang et al. 2009; Lavie et al. 2010; Siggelkow and Levinthal 2003) and are associated with different thinking logic (Wadhwa and Kotha 2006), contexts and cultures (Gibson and Birkinshaw 2004) and leadership styles (Jansen et al. 2009). These tensions arise from the different nature of exploration and exploitation. For instance, exploratory activities rely on current knowledge or break away from existing knowledge to design new products or develop new markets in order to serve emerging customers and markets, while exploitative activities are based on existing knowledge to enhance the organization's existing skills, processes, structure and serve existing customers (Benner and Tushman 2003; Smith and Tushman 2005). Although exploration and exploitation compete for resources in the short run, they are mutually reinforcing in supporting organizational long-run survival (He and Wong 2004). For example, in the process of organizational learning, exploration expands the knowledge base where the exploitation occurs; exploitation improves absorptive capacity and facilitates experimentation where the future exploration lies (Andriopoulos and Lewis 2009). Diversified firms may balance exploration and exploration across various domains (Lavie et al. 2010), while non-diversified firms might achieve prosperity under different modes of operations (Stettner and Lavie 2015) or through external embeddedness and knowledge management (Luca et al. 2018).

Andriopoulos and Lewis (2009) define three aspects of tensions around exploration and exploitation, that is, strategic intent (profit-breakthroughs), customer orientation (tight-loose coupling), and personal drivers (discipline-passion). Integration and differentiation are two viable approaches to manage paradoxes and balance exploration and exploitation. Integration regards exploration and exploitation as interwoven and synergistic, whereas differentiation concentrates on unique aspects of exploration and exploitation separately (Smith and Tushman 2005). Integration is the behavioral mechanism that enables organizations to pursue exploratory and exploitative activities within the same unit through organizational design (Gibson and Birkinshaw 2004) or top management teams (Lubatkin et al. 2006). Differentiation is the division of activities into distinct organizational units or domains fostering either exploration or exploitation (Lavie et al. 2010; Raisch et al. 2009; Tushman and O'Reilly III 1996). For example, through an in-depth case study of five ambidextrous firms, Andriopoulos and Lewis (2009) propose differentiating practices that include building diversified portfolios, iterating between project constraints and freedom, temporally and structurally splitting 
work modes, and integrative practices that include cultivating a paradoxical vision, improvising purposefully as well as nurturing paradoxical identities. Smith (2014) also devises differentiating and integrative leadership practices to manage strategic paradoxes.

Building on the idea of exploration and exploitation as a paradox and taking the examination of the antecedents of exploration and exploitation separately, Koryak et al. (2018) distinguish two types of antecedents of ambidexterity and argue that integrative antecedents contribute to both exploration and exploitation while differentiating antecedents lead to either exploration or exploitation. We move their work one step further and consider that antecedents of exploration and exploitation can be combined together in distinct ways to generate the desired innovative outcomes. Viewed from this angle, antecedents are neither integrative nor differentiating, but are a part of a specific configuration for exploration and exploitation. We name them as configured causal antecedents. This causation logic is consistent with the neo-configurational approach that demonstrates causal complexity by three characteristics: (1) conjunction (multiple antecedents or conditions interdepend on each other to obtain a given outcome); (2) equifinality (there are multiple paths leading to the same results); (3) asymmetry (the presence of a condition or the absence of a causal condition may generate the same outcome) (Misangyi et al. 2017). Moreover, we propose a specific configurational approach, in addition to the integration and differentiation approach, to balance exploration and exploitation in the study on ambidexterity. Under this new approach, firms can decide themselves on the "causal recipes" for exploration and exploitation, thus alleviating tensions between them.

\section{Antecedents of exploration and/or exploitation}

Antecedents of exploration and/or exploitation have attracted attention from many scholars. Lavie et al. (2010) systematically review the antecedents of exploration and exploitation. They find three kinds of antecedents: organization, environment and senior management team. However, as they point out, "empirically, very few factors have been shown to produce consistent effects on these activities (exploration and exploitation)." In addition, they do not examine the interaction or combination effects of these antecedents on exploration and/or exploitation, except that they state that "adverse combinations of environmental forces and organizational pressures may explain organizations' efforts to balance exploration and exploitation." In this present paper, based on Lavie et al. (2010)'s general classification of antecedents, we focus on environmental antecedents and organizational antecedents and their combination effects, that is, what different organizational traits combined with different environmental conditions are desirable for exploration and exploitation. Although managerial antecedents are important, they are not our main focus here. Then, for each category, we choose antecedents that are theoretically significant from the general categories proposed by Lavie and his colleagues. As well, we supplement and improve these categories with concepts, such as entrepreneurial bricolage (related to resources) and organizational life cycle stage (related to age). Next, we will introduce each antecedent and explain why they are central for our analysis.

\section{Environmental antecedents}

Firms constantly interact with external environments to innovate (Craig and Dibrell 2006). Environmental factors that have influence on exploration and exploitation 
include environmental dynamism, exogenous shocks, competitive intensity, and appropriability regimes (Lavie et al. 2010). Exogenous shocks are triggered by sudden and unexpected events that are beyond the control of any organization (Meyer et al. 1990). Because shocks are hard to measure and may not happen during a small firm's lifetime, it is not appropriate to use this category in empirical testing. Competitive intensity refers to the extent to which organizations compete for the same pool of limited resources (Barnett 1997). During periods of fierce competition, exploration is employed as a means for strengthening an organization's market status in existing markets and establishing a presence in new markets whereas the incentives to exploit dominate when the competitive tension is suppressed. Compared with large and established firms in a mature industry, small firms often experience less pressure from competition. Indeed, many small and newly established firms have almost no rivalry at the time they are founded and thus the impact of competitive intensity on small firms' exploration and exploitation may not be significant. Consequently, competitive intensity is also not a good antecedent for our research on small firms. Since our research focuses on small firms in the same political context, appropriability regime does not apply here. Finally, we chose environmental uncertainty to depict the external environment.

Environmental uncertainty includes three dimension: dynamism, heterogeneity and hostility (Miller 1987). It is rooted in changes in the environment, such as customer preferences, technologies, or market demand (Lavie et al. 2010; Jansen et al. 2006) and has a strong influence on a firm's innovation and performance (Chan et al. 2016; Chu et al. 2018; Roper and Tapinos 2016). When the environment is uncertain, the ability to develop new technological capabilities rapidly is more desperately needed (Tushman and Anderson 1986). Responding to environmental uncertainty and variation also requires similar variations in the firm (Daft and Weick 1984). As a result, innovations as variation-increasing activities are important to firms facing environmental uncertainty, leading to firms' choice of exploratory innovations and exploitative innovations (Lin et al. 2007).

Innovations are closely related to environmental conditions. Exploratory innovations are "intended to respond to, as well as drive, latent environmental trends," whereas exploitative innovations are aimed at "responding to current environmental conditions" (Lubatkin et al. 2006: p. 6). Several scholars have explored the effect of environmental uncertainty on exploratory and exploitative innovation. For example, Rowley et al. (2000) argue that uncertain environments impel firms to invest in exploration as environmental uncertainty increases the rate of innovation required to survive. Jansen et al. (2006) propose that the effectiveness of exploratory innovation is enhanced in turbulent and uncertain environments, while exploitative innovation is more conducive in competitive environments.

\section{Organizational antecedents}

Environmental antecedents explain the systematic tendencies of organizations to explore or exploit, but they cannot account for the heterogeneity of organizations' tendencies within the same industry (Lavie et al. 2010). Organizational antecedents consist of organizational structure, slack resources, organizational age and size, organizational culture and identity, etc. (Lavie et al. 2010). Slack resources are excess resources after organizations carry out ordinary operations (Nohria and Gulati 1996). Because small 
firms generally have fewer slack resources than large ones (Chen and Hambrick 1995) and our focus is only on small firms, slack resources as one of the antecedents may not generate much variety and thus is excluded in our analysis. However, the lack of resources forces small firms to make full use of the resources at hand, prompting entrepreneurial resources bricolage behaviors (Baker and Nelson 2005) that are related to innovation. Organizational culture and identity are not only hard to measure, but also have inconsistent influence on exploration and exploitation (Lavie et al. 2010). As a consequence, we selected organizational culture (unit interdependence), entrepreneurial bricolage and organizational age (organizational life cycle stages) as organizational antecedents and explain how they are associated with exploration and/or exploitation.

Unit interdependence Organizational internal structure regulates the allocation of power, resources, and responsibilities across different organizational units of a firm (Lavie et al. 2010). The commonly used measure of organizational structure is mechanic structure vs. organic structure. Mechanistic structure entails routines, specialization, formal duties, and power whereas organic structure emphasizes informal and less rigid establishments (Burns and Wholey 1993). The former facilitates exploitation while constraining exploration (Lavie et al. 2010) and the latter has the reverse effect. However, small firms often adopt a simple structure, characterized by informal coordination, little specialization, low degree of formalization and centralization of power at the top (Miller 1986). This simple structure has many characteristics of the organic structure, limiting small firms' score on mechanistic structure. In addition, structural patterns as a nominal measure cannot capture the inter-unit dynamics linked to organizational adaptation-the general goal of exploration and exploitation (March 1991). More importantly, organizational adaptation is not a "holistic" problem solved by the organization as a whole, but rather an "aggregate" problem which needs to be solved in an ongoing process such as the mutual adjustment of different organizational units (Gresov and Stephens 1993). Therefore, we examine the influence of unit interdependence, instead of the structural patterns of exploration and exploitation.

First proposed by Thompson (1967), unit interdependence refers to the extent to which organizational units or individuals depend on each other. McCann and Ferry (1979) define unit interdependence as a condition where one unit will influence other units' actions and work outcomes. They put forward a transactional view of interdependence that operationalizes the resource transactions (including that of real and budgeted funds, products, support services and information) that occur between units. Victor and Blackburn (1987) describe unit interdependence as the extent to which a unit's outcomes are controlled directly by or are contingent upon the actions of other units. For firms that are confronted with severe resource constraints, the higher the unit interdependence is, the more a certain unit will attempt to use influence and political behaviors to affect the design and operations of other units within the firm (Gresov and Stephens 1993). As well, organizational units also learn from each other, benefit from new knowledge developed by other units, and hence have more opportunities for mutual learning and inter-unit cooperation that stimulate organizational innovation (Tsai and Ghoshal 1998; Tsai 2002). Though the effects of unit interdependence are 
increasingly recognized, little is known about whether this single condition is sufficient to attain exploration and/or exploitation, and, if not, how it combines with other factors to help firms achieve outcome(s).

Entrepreneurial bricolage Innovation requires combining and organizing complementary resources in order to seize and exploit opportunities (Moorman and Slotegraaf 1999). However, most small firms are confronted with severe resource constraints and have difficulties in attracting human, financial, and other resources needed (Penrose 1959). In this unfavorable context, many entrepreneurs in small firms may (have to) embrace or even pursue new challenges (Mahoney and Michael 2005). To solve this puzzle, Baker and Nelson (2005) delineate the concept of entrepreneurial bricolage, which is based on Lévi-Strauss's concept of bricolage-making do with what is at hand (Lévi-Strauss 1967). Defining bricolage as making do by combing resources at hand to new problems and opportunities, Baker and Nelson insist that firms engaged in bricolage typically create something from nothing by utilizing physical, social, or institutional resources that other firms have rejected or ignored. Firms often find value from these kind of resources because they are able and willing to test and reject institutional constraints and definitions.

Through the process of combining existing but disparate resources for new purposes, entrepreneurial bricolage serves as a mechanism for innovation, bringing about new "services" from existing resources (Senyard et al. 2014; Salunke et al. 2013; Witell et al. 2017). A large proportion of the literature highlights its effects on exploratory innovation, with less attention on exploitative innovation (Guo et al. 2016; Ravishankar and Gurca 2016). Turturea et al.'s (2014) work that emphasizes entrepreneurial bricolage's positive effects on both exploration and exploitation is an exception. However, as Baker and Nelson (2005) argue, when firms use parallel bricolage, i.e., multiple ongoing projects relying on bricolage, they may form a mutually reinforcing community and self-identity, constraining their further exploration of new resource combinations and opportunities from outside the community. On the contrary, if firms utilize selective bricolage, i.e., limiting bricolage into two or three domains, they avoid the self-reinforcing cycles of parallel bricolage. As a result, more disruptive new combinations might come into being.

Organizational life cycle stage The organizational life cycle stage is another antecedent of exploration and/or exploitation. Pressures, threats and opportunities in the external and internal environment and needs of resources vary with the organizational life cycle stages (Jawahar and McLaughlin 2001), resulting in different organizational behaviors. For example, in different life cycle stages, firms have different strategies and structures (Chandler 1962). Priorities of top management also change with firms' life cycle stages (Smith et al. 1985). As well, an organizational life cycle stage may influence a firm's innovation behaviors. When firms are in the early stage of their life cycle, e.g., start-up stage, they react to the demands of customers by growing and selling new items (i.e., innovative goods and services) (Dibrell et al. 2011) and are often associated with increasing levels of innovation (Govindarajan and Trimble 2005). This is consistent with the finding that younger firms prefer to develop riskier innovation, e.g., exploration, which is associated with higher returns and greater losses (Coad et al. 2016). 
On the contrary, older firms are likely to possess rigid routines and structures that constrain exploration (Nelson and Winter 1982). SMEs that are in the later stages of the organizational life cycle often find it hard to overcome these barriers to change; therefore, their innovativeness will decline (Dibrell et al. 2011). However, it does not mean that these firms no longer innovate. Instead, they may undertake exploitative innovation. Sørensen and Stuart (2000) conclude that aging is related to higher rates of innovation, but this kind of innovation is obsolete relative to the current environment because aging firms have difficulties in keeping pace with the environment. Nerkar (2003) also shows that older firms' information-processing routines encourage them to innovate in their existing technology fields rather than in new ones. Hence, we posit that firms in their early life stages, such as the seed stage, are likely to undertake exploratory innovation while in a later life stage are inclined towards exploitative innovation.

\section{Interaction of multiple antecedents}

Research on organizational adaptation has argued that in the face of environmental and technological change, firms have to change internal and external structural alignments in order to survive and thrive (Tushman and O'Reilly 2002). In fact, when there are adverse combinations of environmental factors and organizational combinations, firms will experience more pressures to balance exploration and exploitation (Lavie et al. 2010). In line with the causal complexity from a neo-configurational perspective and the argument of Kauppila (2010) that in the real world, firms often combine contextual and structural antecedents to balance exploration and exploitation, we presuppose that these four antecedents are interrelated with each other to achieve exploration and exploitation. For example, entrepreneurial bricolage is associated with resources at hand (Baker and Nelson 2005), while organizational structure, e.g., unit interdependence regulates the flow of resources which are the basis for bricolage behaviors. Consequently, we aim at unraveling this causal complexity by utilizing the QCA method in our analysis. We come up with the third approach - configurational approach - that is to figure out different paths to exploration and exploitation in order to help find a balance between exploration and exploitation.

In sum, environmental uncertainty, unit interdependence, entrepreneurial bricolage and organization life cycle stage are four factors or causal conditions that are of high salience in exploration and/or exploitation. These factors are likely intertwined and interrelated to each other. The next section explains the data and methodology we use in addressing our research question: How do antecedents of exploration and/exploitation combine to form various paths to exploration and exploitation in organizations?

\section{Empirical analysis}

\section{Sample and data collection}

Small firms in China provides a suitable context for understanding our research question. First, contrary to those in mature, established large firms, the paradoxical tensions between exploration and exploitation might be more obvious in small firms, because they seldom have enough resources to allocate between exploratory and exploitative activities (Mosakowski 2017; Penrose 1959). When dealing with contradictory demands in resource allocation as well as other issues, founders and high level managers of small 
firms may experience more tension. Second, entrepreneurial bricolage behaviors are more prevalent in small firms because they often experience a shortage of resources (Senyard et al. 2014). Therefore, small firms may produce more variety in key organizational variables, especially entrepreneurial bricolage. Finally, small firms in emerging countries are developing fast, making small firms an important object of study (Senik et al. 2011). Following this sample selection criterion and considering that the outcome variable in our research is exploratory and exploitative innovation, we mostly include firms that are small, young and innovative in our sample.

The data collection process consists of several stages. First, in the questionnaire design stages, key concepts in the questionnaire were adapted from mature scales in English and modified slightly to correspond to the Chinese research context (see details in the "Measures and calibration" section). To ensure translation validity, we used back-translation by four English-major graduates and one expert scholar. Before sending out the questionnaires on a large scale, we discussed them with several entrepreneurs to further improve the quality. To reduce potential response biases, we avoided putting items that belong to the same construct together and adjusted the sequence of the questions. We also set several opposite questions, which act as "anchor" questions to see if respondents are serious in their answers. Second, we adopted a snowball sampling method. Snowball sampling is often used to investigate rare groups. In our research, founders or high-level managers of small firms are hard to access, partly because they are not required to reveal personal information, nor do they have incentives to do so. In addition, most small firms are short-lived and scattered over diverse industries and geographical regions, adding to the difficulty of gathering information. However, founders of small firms often know other founders because of business cooperation, taking part in business conferences, receiving MBA education together and so on. They tend to be interested in expanding social networks in order to discover and exploit entrepreneurial opportunities (De Carolis and Saparito 2006). By using a snowball sampling method - contacting founders or the high-level managers that we knew and then asking them to recommend other entrepreneurs or high-level managers, we were able to get in touch with more and different respondents, improving the representativeness of our sample. The whole process lasted for no more than 1 month, eliminating potential time difference problems. In the end, we collected questionnaires from 95 firms, which are representative of today's young, small, active and innovative firms: They are located in different provinces/ municipalities including Beijing, Tianjin, Shanghai, Guangdong, Jiangsu, Shanxi, Hubei, Henan and Shandong and spread over manufacturing, service and other industries. Most of them were established after 2000 and have R\&D/ sales ratio higher than $4 \%$. After checking the questionnaires collected, we manually filtered out 32 obviously unqualified ones (they were not filled in seriously by the respondent or there were missing data), leaving 63 firms for next-step empirical analysis.

\section{Analytical approach}

Based on the data gathered, this paper adopts fsQCA. ${ }^{1}$ QCA builds on set theory and views each case as constellation of interconnected elements (configuration) with a particular outcome and then utilizes the truth table and Boolean algebra to minimize configurations (Fiss 2011). In contrast with the traditional regression method that 
emphasizes "linear" and "cumulative" ways of thinking and consider the "net effect" of an independent variable, QCA uses Boolean operations to express causal relationships and analyzes multiple interaction effects of different conditions to explain the outcome. In addition, regression deals with correlation rather than causation, while QCA paves the way for causal analysis (Ragin 2008).

QCA is chosen for our research for the following reasons: (1) As a configurational approach, QCA embraces causal complexity explicitly, and thus is suitable for our neo-configurational perspective and fits well with our research question investigating complex combinations among different antecedents of exploratory and/or exploitative innovation. In this case, a traditional regression method does not apply because it is not good at producing robust results for multiple interactions; (2) QCA goes beyond the limitations of qualitative and quantitative studies and has the strengths of the two. It is regarded as a third sound research method in the field of social science (Ragin 2014); (3) QCA matches our sample. QCA does not require a large sample size or normal distribution of the sample as regression does, facilitating in-depth knowledge of each case.

\section{Measures and calibration}

Because qualitative comparison analysis uses set data, all variables must be calibrated to different sets. Therefore, before our formal analysis, variables should be calibrated in fuzzy sets or multi-value sets, according to criteria that reflects meaningful qualitative distinctions (Ragin 2008). In the calibration process, fuzzy set variables should be calibrated into different sets and the resulting variables ranging from 0 to 1 represent various set memberships: "1" represents a variable that belongs to a set ("fully in"); "0" signifies a variable that does not belong to a set ("fully out"); "0.5" denotes the crossover point (neither fully "in" nor "out" of a given category). Multi-value variables such as the life cycle stage of firms is converted to integers from 0 to 3 , with each integer denoting a distinctive life stage.

We adopted the direct calibration method proposed by Ragin (2008) and specified three qualitative distinction points - " 0 ", " 0.5 " and " 1 ", corresponding to three values of the raw variables. Then, the software performed the logistic function and transformed the remaining raw variables to fine-grained calibrated variables. Designating the three qualitative distinction points relies on theoretical and substantive knowledge, or the characteristics of the sample distribution, usually the mean, median or the quartiles (Ragin 2008). Although external knowledge (substantial or theoretical) is often employed in calibration, according to Campbell and his colleagues's (Campbell et al. 2016) research on acquisition premium, if there is no external knowledge, calibration can be carried out based on the distribution of the sample. In this paper, we take both substantive knowledge and sample characteristics into consideration. That is, we first relied on substantive knowledge (based on our questionnaire design, e.g., 6-point Likert scale) to calibrate. Only when the sample deviates too far from this substantial knowledge, did we take the sample characteristics into consideration. In the following, we will describe the measurement and calibration of key variables of interest.

\section{Exploration and exploitation}

Referring to the research conducted by Lubatkin and his colleagues (Lubatkin et al. 2006), we operationalized exploration and exploitation utilizing 12 items scales, 6 items 
for exploration and 6 items for exploitation. Then, we used a 6-point Likert scale ${ }^{2}$ and asked the respondents to evaluate the items from 1 to 6 (strongly disagree to strongly agree). Lacking relevant theoretical knowledge, we relied on substantive knowledge and sample distribution to calibrate. In line with our survey questions (substantive knowledge), 6 means fully in the set of exploration or exploitation, while 1 is fully out of the set and 3.5 is the crossover point. However, when examining the sample distribution, most of the respondents have scores higher than 3 . This is probably because they cannot clearly distinguish between exploration and exploitation due to the common nature of exploration and exploitation as innovation. Therefore, we increased the qualitative distinction points in order to capture meaningful distinctions. In terms of the crossover point, the difference between the sample mean (4.74 for exploration and 4.84 for exploitation) and 3.5 is very large; we therefore prefer to use the sample mean as the crossover point. As a result, based on sample distribution, we set the threshold for exploration (i.e., fully in) at 6 , the crossover point at 4.74 (mean), and fully out at 3 . We also set the threshold for exploitation (i.e., fully in) at 6 , the crossover point at 4.84 (mean), and fully out at 3 . The resulting configuration was more simple and clean, satisfying the criteria proposed by Ragin (2008) when comparing different results.

\section{Environmental uncertainty}

Following Zhang and Li (2010), we measured environmental uncertainty using 3 item scales and asked respondents using a 6-point Likert scale to rate the statements about the principal industry that their firm has been in over the last three years in terms of technology uncertainty, competitors' actions and product market conditions. Ideally, in the 6-point Likert scale, 3.5 represents the most ambiguity, 1 is fully out of the set of environmental uncertainty and 6 is fully in the set of environmental uncertainty. In the absence of theoretical knowledge, these three numbers are qualitative distinction points by themselves. However, when looking into our sample, no respondent has a score of 1 . Therefore, we selected score 6 as fully in (high environmental uncertainty) and 2 instead of 1 , as fully out. Although we took the sample distribution into account in selecting the crossover point, we aimed to approach the ideal and natural mean, which is 3.5 (mean of 1 and 6) by the design of the 6-point Likert scale. Under this condition, if the difference between the sample mean and 3.5 is not very large, we prefer to use 3.5 as the crossover point. If the difference between the sample mean and 3.5 is very large, we will set the sample mean as the crossover point. In fact, the sample mean for environmental uncertainty is 3.8 , which is close to 3.5 . When we set 3.8 as the crossover point, ceteris paribus, the QCA result is almost the same. As a result, score 6 was selected as the threshold for fully in, 2 as fully out, and 3.5 (mean) as the crossover point.

\section{Unit interdependence}

We opted for unit interdependence as an alternative measurement of organizational internal structure. Unit interdependence was measured according to the scale developed by Gresov and Stephens (1993). The scale captures information and materials flow and task interdependence between different organizational units. Due to the lack of theoretical knowledge, we utilized three qualitative distinction points-6, 3.5 and 1-which are ideal qualitative distinction points. However, considering the sample distribution (no 
respondents chose 1 , and only very few people have scores lower than 3 , meaning that 1 is not appropriate as the fully out point), we again set 2 , rather than 1 , for fully out of the set of unit interdependence. In terms of the crossover point, the sample mean for unit interdependence is 3.68 , which is very close to 3.5 . Therefore, we used 3.5 as the crossover point. Results still hold in the case of 3.68 as the crossover point. In the end, 6 is the threshold for fully in, 2 is fully out, and 3.5 (mean) is the crossover point.

\section{Entrepreneurial bricolage}

When measuring entrepreneurial bricolage, we took advantage of the scale developed by Senyard et al. (2009). Short of theoretical knowledge, we calibrated entrepreneurial bricolage according to substantial knowledge and sample distribution. Because the average score is 4.64 , and no respondents have a score lower than 3 , signifying that the score for entrepreneurial bricolage is generally higher among small firms. So, we raised up the fully out point to 3 in order to create a meaningful distinction of set membership in entrepreneurial bricolage. At the same time, because the difference between the samples mean (4.64) and the ideal mean (3.5) is very large, we chose 4.64 as the crossover point. Consequently, score 6 was selected as the threshold for fully in, 3 for fully out, and 4.64 as the crossover point.

\section{Firm life cycle stage}

Drawing on the life cycle theory (e.g., Kazanjian 1988) and the fact that our sample firms are relatively young, we divided the organizational life cycle into four stages: seed stage, start-up stage, development stage and maturity stage, according to organizational main tasks, product maturity, sales volumes and so on. As firm life cycle stage is a multi-value variable, we assigned 0 to the seed stage, 1 to the start-up stage, 2 to the development stage and 3 to the maturity stage $(0,1,2$ and 3 are nominal variables).

\section{Analyses}

\section{Analysis of the necessity}

To determine whether a single antecedent/condition is enough to produce the result, we used QCA software to calculate the necessity of each individual condition. As shown in Table 1, the necessity of each individual condition is no more than 0.9 . That is, all the individual conditions do not constitute a necessary condition for either exploration or exploitation. However, each condition's necessity level is generally high, indicating that the condition is relatively important for interpreting the specific outcome. This implies the rationality to examine the substitution and supplementary effects between conditions from a configurational perspective and identify the "INUS" conditions. Hence, we conducted the fsQCA in the next step.

\section{Fuzzy set qualitative comparative analysis (fsQCA)}

The primary analyses in this study were carried out with the QCA (GUI) package in R (Dusa 2007). The next step after calibration is to create a "truth table," where each case represents a configuration of different causal factors or conditions. In theory, there are $2^{\mathrm{k}}$ logically possible combinations in Boolean property space ("0" represents absence of a condition while "1" signifies presence of a condition) and $k$ is the number of causal 
Table 1 Necessity of each single antecedent

\begin{tabular}{llll}
\hline Antecedents & Notation & Exploration & Exploitation \\
\hline Stage & Stage 1 & 0.26 & 0.27 \\
& Stage 2 & 0.27 & 0.31 \\
& Stage 3 & 0.33 & 0.32 \\
& Stage 4 & 0.15 & 0.10 \\
Unit Interdependence & $\sim U$ UI & 0.69 & 0.70 \\
Environmental Uncertainty & UI & 0.76 & 0.80 \\
& $\sim$ EU & 0.67 & 0.66 \\
Entrepreneurial Bricolage & EU & 0.75 & 0.81 \\
& $\sim$ EB & 0.60 & 0.66 \\
\hline
\end{tabular}

Notes. " " indicates the logical "No", i.e., the negation of the specified antecedent

conditions (Greckhamer et al. 2008). In our paper, four causal conditions generate 32 possible configurations (life cycle stage is a multi-value variable and hence roughly equals to two conditions).

Configurations to be analyzed in deriving the solutions for a specified outcome must pass the frequency threshold and consistency threshold. Frequency threshold means that a configuration must be covered by at least $n$ number of cases. If a configuration does not pass the threshold, it will be treated as a logical remainder. ${ }^{3}$ When the number of cases is large, a higher frequency threshold should be considered (Berg-Schlosser et al. 2009). As a result, we set the frequency threshold at 3 cases, which encompass $80 \%$ of our cases, satisfying the criteria that least $80 \%$ of cases should be retained (Ragin 2008; Campbell et al. 2016). Consistency evaluates how well a perfect subset relationship is approached and measures the degree to which the statement of sufficiency or necessity is in line with the empirical evidence (Ragin 2000). In other words, consistency refers to the degree to which cases that share the same combination of conditions consistently bring about the outcome of interest. Low consistency means that a given configuration is not reliably and consistently producing the outcome of interest, while high consistency signifies that a given configuration consistently generates the outcome of interest (Campbell et al. 2016). We set the consistency threshold at 0.85, higher than 0.8 used by Fiss (2011) and Campbell et al. (2016), in order to generate more robust results.

Finally, we started to run the Boolean minimization algorithm. Based on a counterfactural analysis of logical remainders, three kinds of solutions are obtained: complex, parsimonious and intermediate. Counterfactural analysis is used to analyze the logical remainders and assign outcome values to them in order to simplify solutions. If researchers do not make a counterfactural analysis, then the complex solution will be derived because logical remainders are not included in the analysis; if researchers make both "easy" and "difficult" counterfactual analyses, then the parsimonious solution will be reached. The intermediate solution lies between the complex solution and parsimonious solution and only employs easy counterfactuals analysis. Following extant research (Fiss 2011; Misangyi and Acharya 2014; Campbell et al. 2016), we report an intermediate solution made up of core conditions and peripheral conditions. 
Core conditions appear in both the intermediate and the parsimonious solution, while peripheral conditions do not show in the parsimonious solution. These two types of conditions are distinguished using different signs in the Results section, i.e., a large circle for core conditions and a small circle for peripheral conditions (Fiss 2011; Campbell et al. 2016).

\section{Results}

In Table 2, we display the configurations of conditions associated with exploration and exploitation. ${ }^{4}$ Each column represents a distinct configuration. According to Ragin's (2008) proposal, Table 2 only reports the intermediate solutions consisting of core and peripheral conditions.

QCA results show that the four conditions combine to generate seven different paths leading to the outcome of interest, which signifies the conjunction in causal complexity (Misangyi et al. 2017). Specifically, four different configurations (i.e., 1-4) generate exploration while three different configurations (i.e., 5, 6a and 6b) produce exploitation, indicating the equifinality in causal complexity (Misangyi et al. 2017).

Two main indicators are employed to assess the set-theoretic relationship consistency and coverage. As we mentioned earlier, consistency refers to the degree to

Table 2 Configurations of exploration and exploitation

\begin{tabular}{|c|c|c|c|c|c|c|c|}
\hline \multirow{2}{*}{ Causal conditions } & \multicolumn{4}{|c|}{ Configurations of exploration } & \multicolumn{3}{|c|}{ Configurations of exploitation } \\
\hline & 1 & 2 & 3 & 4 & 5 & $6 a$ & $6 b$ \\
\hline \multicolumn{8}{|l|}{ Life cycle stage } \\
\hline \multicolumn{8}{|l|}{ Seed stage } \\
\hline Start-up stage & & & & & $\bullet$ & & \\
\hline Development stage & & 0 & & 0 & & $\bullet$ & \\
\hline \multicolumn{8}{|l|}{ Maturity stage } \\
\hline Environmental Uncertainty & & & $\bullet$ & $\bullet$ & $\otimes$ & & $\bullet$ \\
\hline Unit Interdependence & $\otimes$ & & & O & $\otimes$ & $\bullet$ & $\bullet$ \\
\hline Entrepreneurial Bricolage & O & 0 & O & & O & O & ○ \\
\hline Consistency & 0.89 & 0.90 & 0.87 & 0.87 & 0.88 & 0.93 & 0.97 \\
\hline Raw coverage & 0.28 & 0.62 & 0.19 & 0.19 & 0.22 & 0.64 & 0.18 \\
\hline Unique coverage & 0.06 & 0.34 & 0.08 & 0.02 & 0.04 & 0.13 & 0.04 \\
\hline $\begin{array}{l}\text { Overall solution } \\
\text { consistency }\end{array}$ & & & & & & 0.85 & \\
\hline Overall solution coverage & & & & & & 0.84 & \\
\hline
\end{tabular}

Notes. Black circles 
which cases that share the same combination of conditions consistently bring about the outcome of interest. Coverage assesses the extent to which the instances of the outcome are explained by a certain path (Ragin 2008). Further differentiated, raw coverage denotes memberships in the outcome that are covered by a single path or configurations, while the unique coverage explains memberships in the outcome that are not covered by other paths or configurations (Ragin 2008). As evidence for the set-theoretic relationships indicates in Table 2, the overall consistency of configurations is 0.88 for exploration and 0.85 for exploitation, satisfying the acceptable consistency score of 0.8 (Fiss 2011). The overall coverage is 0.82 for exploration and 0.84 for exploitation. Consistency and coverage score of each individual configuration are also shown in Table 2.

\section{Overall effects of antecedents}

Each of the four conditions - including environmental uncertainty, life cycle stage, unit interdependence and entrepreneurial bricolage - does not present itself as a solely sufficient antecedent in configurations of exploration or those of exploitation, confirming our statement that there are no absolute differentiating antecedents. In addition, each of the same set of antecedents does not exist in all configurations for exploration and exploitation, suggesting that integrative antecedents do not exist either. Every antecedent combines with others as insufficient yet necessary (i.e., equifinal) conditions, and can be expressed as an "INUS" antecedent if it appears in the solution of exploration or exploitation. In total, seven configurations that, without exception, show the patterns of casual complexity, are generated via QCA.

\section{Configurations for exploration}

Entrepreneurial bricolage, although not individually sufficient, is a highly necessary condition for the presence of both exploration and exploitation. This condition appears as a core antecedent in six configurations out of seven configurations. However, whether it contributes to exploration or exploitation depends on how it combines with other conditions.

As we can see from Table 2, in configuration 1, when organizational units are not interdependent, the presence of entrepreneurial bricolage is sufficient to bring about exploration. In this case, different organizational units can get demanded resources through entrepreneurial bricolage, without being subject to the influence attempts of other organizational units. In configuration 2, small firms in the development stage can take advantage of entrepreneurial bricolage to become explorative. The underlying reasoning may be that firms in this stage are faced with much pressure to enter into new markets and serve more customers. Once they have resources at hand, they may combine them improvisationally to sense and seize new opportunities. In configuration 3, with the presence of environmental uncertainty, firms in the seed stage will be explorative once they can bricolage resources. If not taking bricolage as a necessary step, as shown in configuration 4, firms in the development stage could still be explorative under the conjoint conditions of environmental uncertainty and high levels of unit interdependence. The underlying rationale might be that firms in the development stage are relatively mature and organizational units in those firms can exchange resources and learn from each other (Tsai and Ghoshal 1998) to get sufficient resources and ideas for exploration. 
In comparison with configurations 1, 2 and 3, which function as a kind of bricolage-induced exploration, the explorative innovation reflected by configuration 4 is named as unit-mutual-learning exploration. The latter is equifinal with the former, although its rate of coverage is lower (see Table 2).

In sum, for small firms that lack resources, when their internal organizational units are interdependent, or when they are in the seed stage with environmental uncertainty or have moved into the development stage, they may have a better chance to explore once they undertake entrepreneurial bricolage as a necessary step to lessen resource constrains; equifinally, when firms are in the development stage and facing environmental uncertainty, the presence of unit interdependence as a core antecedent coupled with the two contextual conditions will be sufficient to achieve exploration. Interestingly, when the environment is uncertain and, for simplification, ignoring the life cycle stage, a partial substitution effect between entrepreneurial bricolage and unit interdependence emerges in configurations for exploration, as the two provide alternative channels of innovation resources for innovative units within small firms.

\section{Configurations for exploitation}

As the right part of Table 2 indicates, entrepreneurial bricolage is necessary for all the three exploitation configurations. Specifically, for configuration 5, when a small firm is in the start-up stage, its entrepreneurial bricolage behaviors together with the absence of both environmental uncertainty and the absence of unit interdependence, will sufficiently give rise to exploitation. In this case, even though a firm is in the start-up stage and actively combines different resources for a new purpose, given that its environmental uncertainty is low and each unit is not strongly influenced by others, the firm may concentrate on consolidating its current status in existing fields, with a fear that too much exploration is both risky and costly. As for configuration $6 \mathrm{a}$ and $6 \mathrm{~b}$, they are "neutral permutations" (sharing the core condition and only differing in their peripheral conditions). Unit interdependence and entrepreneurial bricolage appear conjunctionally in these two configurations. The reasoning behind is that small firms will lock themselves in the status of exploitation when in an uncertain environment or in the development stage. Under this circumstance, unit interdependence serves as an undifferentiated necessary condition that is complemented by entrepreneurial bricolage.

\section{Comparison across configurations for exploration and exploitation}

Substitution effect of entrepreneurial bricolage and unit interdependence in explaining exploration

The general pattern emerging from the overall comparison is the different relationships between entrepreneurial bricolage and unit interdependence. These two antecedents are partial substitutes in explaining exploration as shown in the left part of Table 2. If small firms expect to achieve exploration through the enabling condition of entrepreneurial bricolage, they either do not need to make the internal organizational units interdependent at all (configuration 1), or they do not care about the presence or absence of this internal condition (configurations 2 and 3). This finding is consistent with the statement in entrepreneurship literature that unit interdependence as the main aspect of organizational structure is generally irrelevant (Green et al. 2008; Ireland et al. 2009). By comparison, when entrepreneurial firms grow up to the development stage 
and have designed a formal structure to enhance unit interdependence, entrepreneurial bricolage becomes no longer necessary for achieving exploration (configuration 4), suggesting that unit interdependence and entrepreneurial bricolage are substitutes.

To further illustrate the substitution effect, first, we distinguished different conjunctional states of unit interdependence and entrepreneurial bricolage. As shown in Table 2, the "exploration" outcome results from configurations 2 and 3, regardless of the presence and absence of unit interdependence, or from configuration 4, indifferent to the presence and absence of entrepreneurial bricolage. After we artificially added the absence of Unit Interdependence to configurations 2 and 3 (where the presence of Entrepreneurial Bricolage as well as the other antecedents are supposed to be coupled with the absence of Unit Interdependence to convincingly show the substitution effect) and add the absence of Entrepreneurial Bricolage to configuration 4 (where the presence of Unit Interdependence as well as the other antecedents are expected to be coupled with the absence of Entrepreneurial Bricolage to clearly show the substitution effect), the outcome remains unchanged. That is, with the added "no care" conditions, we get configuration $2^{*}=\{$ Stage * $\sim$ Unit Interdependence * Entrepreneurial Bricolage $\}$, configuration $3^{*}=\{\sim$ Stage * Environmental Uncertainty * Unit Interdependence * Entrepreneurial Bricolage $\}$ and configuration 4 * $=\{$ Stage * Environmental Uncertainty * Unit Interdependence * $\sim$ Entrepreneurial Bricolage $\}$ that is contrasted with configurations $2^{*}$ and $3^{*}$. Each configuration satisfies the consistency thresholds. Therefore, the substitution effect exists in explaining exploration. The only alteration lies in the solutions' statistics.

Second, we calculated the compounded results. As shown in Table 3, we calculated the consistency and coverage of configurations $2^{*}$ and $3^{*}$ equipped with the coupled condition of $\sim$ Unit Interdependence and Entrepreneurial Bricolage. We also computed overall effects of configuration $2^{*}+3^{*}$ and the further configuration $1^{*}+$ $2^{*}+3^{*}$. As shown in Table 3, the compound results are good, proving our conclusion on the substitution effect. In an analogous manner, we calculated the consistency and coverage of configuration $4^{*}$. It has the coupled conditions of Unit Interdependence and $\sim$ Entrepreneurial Bricolage and thus signifies the reverse

Table 3 Supplementary analysis on substitution effects

\begin{tabular}{|c|c|c|c|}
\hline Configurations & Outcome $=$ Exploration & Consistency & Coverage \\
\hline$\overline{2^{*}}$ & Stage $^{*}$ Unit Interdependence $e^{*}$ Entrepreneurial Bricolage & 0.93 & 0.44 \\
\hline $3^{*}$ & $\begin{array}{l}\sim \text { Stage* Environmental Uncertainty* } \sim \text { Unit Interdependence* } \\
\text { Entrepreneurial Bricolage }\end{array}$ & 0.90 & 0.42 \\
\hline $2^{*}+3^{*}$ & $\begin{array}{l}\text { Unit Interdependence }{ }^{*} \text { Entrepreneurial Bricolage* } \\
\text { (Stage }+\sim \text { Stage }^{*} \text { Environmental Uncertainty) }\end{array}$ & 0.90 & 0.58 \\
\hline $1^{*}+2^{*}+3^{*}$ & $\begin{array}{l}\sim \text { Unit Interdependence }{ }^{*} \text { Entrepreneurial Bricolage* } \\
\left(1+\text { Stage }+\sim \text { Stage }^{*} \text { Environmental Uncertainty }\right)\end{array}$ & 0.90 & 0.62 \\
\hline $4^{*}$ & $\begin{array}{l}\text { Stage* Environmental Uncertainty*Unit Interdependence }{ }^{*} \\
\sim \text { Entrepreneurial Bricolage }\end{array}$ & 0.87 & 0.35 \\
\hline
\end{tabular}

Notes. The " $\sim$ " marked conditions in an italic font represent conditions or antecedents that are artificially added into corresponding solutions (configurations 2, 3 and 4) and therefore form more complex configurations (configurations $2^{*}$, $3^{*}$ and $4^{*}$ ) than those in Table 2 . Because "stage" is a multi-value variable, we convert it to a fuzzy set when manually calculating the configurations' consistency and coverage. We use the indirect calibration method proposed by Ragin (2008) and assigned $0,0.33,0.67$, and 1 to the seed, start-up, development and maturity stage, respectively. " 0 " means "fully out" of the set of maturity stage; "1" means "fully in" the set of maturity stage; "0.33" signifies more "out" than "in"; "0.67" denotes more "in" than "out" 
substitution effect. In the end, it is convincing that the substitution between unit interdependence and entrepreneurial bricolage for exploration is symmetric. However, to be more conservative in interpreting our initial results shown in Table 2, we prefer the expression of "partial substitution" to "substitution" as a basic conclusion.

The reason for entrepreneurial bricolage and unit interdependence to partially substitute for each other underlies the similarity of functionality. That is, they both provide resources for exploration, no matter that the source of the resources is the combination of resources available to the focal unit for a new purpose or from other organizational units. Moreover, interdependence on related units may exert constraints on the focal unit's exploratory innovation (Emerson 1962; Ouchi 1977). Therefore, the condition of unit interdependence appears necessary only for those firms that are in the development stage and are facing environmental uncertainty.

\section{Complementary effect of entrepreneurial bricolage and unit interdependence in explaining exploitation}

Configurations $6 \mathrm{a}$ and $6 \mathrm{~b}$ are complementary since they demonstrate the co-existence of entrepreneurial bricolage and unit interdependence. As shown in Table 4, the overall consistency and coverage rate of the consolidated configuration, that is $6 a+6 b=\{$ Unit Interdependence * Entrepreneurial Bricolage * (Stage + Environmental Uncertainty)\}, is 0.93 and 0.69 , respectively. When the internal organizational units are highly interdependent, each organizational unit can access more resources exchanged from other units and then use the resources in the bricolage process. Thus, the consequent entrepreneurial behaviors would be more prevalent. However, this bricolage behavior is probably driven, to some extent, by mutually supported relationships within firms and contribute to forming a permissive community of practice and bricolage identity (Baker and Nelson 2005), which in turn functions as an institutional frame to enhance an extant organizational structure, i.e., unit interdependence. With high levels of unit interdependence that tend to make the interlinked units constrained and controlled by each other (Emerson 1962; Ouchi 1977), the focal units' explorative actions are disturbed or even disabled even though they have a strong desire to explore under conditions of environmental uncertainty. However, due to the presence of entrepreneurial bricolage, the focal unit is still innovative, but only in mature technologies and markets, instead of in new and emerging markets. This is in accordance with the phenomenon that organizational units which are highly interdependent find themselves lacking freedom to act individually and autonomously and tend to exploit rather than explore. As a

Table 4 Supplementary analysis on complementary effects

\begin{tabular}{llll}
\hline Configurations & Outcome $=$ Exploitation & Consistency & Coverage \\
\hline $6 a$ & Stage*Unit Interdependence* Entrepreneurial Bricolage $^{*}$ & 0.93 & 0.45 \\
$6 \mathrm{~b}$ & $\begin{array}{l}\text { Environmental Uncertainty*Unit Interdependence* } \\
\text { Entrepreneurial Bricolage }\end{array}$ & 0.93 & 0.63 \\
$6 \mathrm{a}+6 \mathrm{~b}$ & $\begin{array}{l}\text { Unit Interdependence* Entrepreneurial Bricolage * } \\
\text { (Stage + Environmental Uncertainty) }\end{array}$ & 0.93 & 0.69 \\
\hline
\end{tabular}

Notes. Because "stage" is a multi-value variable, we convert it to a fuzzy set when manually calculating the configurations' consistency and coverage. We use the indirect calibration method proposed by Ragin (2008) and assigned $0,0.33,0.67$, and 1 to the seed, start-up, development and maturity stage, respectively. " 0 " means "fully out" of the set of maturity stage; " 1 " means "fully in" the set of maturity stage; "0.33" signifies more "out" than "in"; " 0.67 " denotes more "in" than "out" 
result, despite the attempts to combine the resources at hand through entrepreneurial bricolage, each focal unit engages in exploitation instead of exploration, promoting exploration of the organization as a whole.

The above complementary effect is not fully necessary for exploitation. As shown by configuration 5 , entrepreneurial bricolage and unit interdependence are not required to co-exist. Those firms in the start-up stage and facing low levels of environment uncertainty tend to exploit in the absence of unit interdependence. Therefore, to be more rigorous, we propose that when firms are in the development stage or their external environment is uncertain, entrepreneurial bricolage and unit interdependence are complementary.

\section{Discussion and conclusion}

This paper starts from research on the antecedents of ambidexterity. Incorporating neo-configuratioal thinking into the paradoxical view of ambidexterity, we extend the work of Koryak et al. (2018) that proposed integrative antecedents and differentiating antecedents of exploration and/or exploitation. We admit that separately examining the antecedents of exploration and exploitation, as well as distinguishing differentiating antecedents from integrative antecedents, is a strategy that may be more conducive to finding a balance between exploration and exploitation in the process of obtaining ambidexterity. However, by adopting a neo-configuration perspective (Misangyi et al. 2017) and employing the QCA method, we believe that there are no absolute integrative or differentiating antecedents. Rather, each antecedent comes into play through the combination with others (contrary to the "net effect" in regression), reflecting the conjunction in causal complexity (Misangyi et al. 2017). Furthermore, there are multiple paths or configurations (contrary to one single model in regression) leading to exploration and exploitation.

To provide empirical evidence for our postulation, relying on previous literature, we discerned four antecedents that are important and necessary to exploration and/or exploitation, namely, environmental uncertainty, entrepreneurial bricolage, unit interdependence and firm life cycle stage. Then, employing data from 63 small firms' founders and high-level managers, we ran the QCA and conclude that: (1) the four conditions do not present solely in all the resulting configurations for exploration and exploitation, suggesting that integrative and differentiating antecedents do not exist. Rather, each antecedent combines with others acting as conjoint causes for exploration and exploitation and is named configured causal antecedents; (2) there are multiple, equifinal paths leading to exploration and exploitation, with each configuration/path as a unique arrangement of antecedents; (3) the relationship between entrepreneurial bricolage and unit dependence is heterogeneous in configurations for exploration and exploitation, that is, they are partial substitutes in configurations for exploration whereas complements in those for exploitation.

\section{Theoretical contributions}

Our research contributes to the current literature in the following aspects:

First, we shed light on the study of ambidexterity. Different from the current literature that treats ambidexterity as a unifying construct (Raisch and Birkinshaw 2008; 
Lavie et al. 2010; Stettner and Lavie 2015), this paper tries to open the box of ambidexterity and separately examine its constituents - exploration and exploitation. Although the previous work of Koryak et al. (2018) has investigated exploration and exploitation individually, it considers the antecedents either integrative or differentiating. We posit that there might be another type of antecedent, called "configured causal antecedents" and a third approach to study them in order to help balance exploration and exploitation, i.e., the configurational approach. Moreover, we discover that there are multiple equifinal paths to exploration and exploitation. These findings deepen our current understanding of ambidexterity.

Second, we add the improvisational way of resource combination, entrepreneurial bricolage, as one of the organizational antecedents, instead of just considering the stock of slack resources. Entrepreneurial bricolage is a relatively new concept proposed by Baker and Nelson (2005). By coupling it with unit interdependence, another organizational antecedent, we look into the inner organization and uncover how composite antecedents combine to achieve exploration and exploitation. We find interesting partial substitution and complementary effects between them, advancing current knowledge of the interplay of organizational structure and entrepreneurial bricolage and their conjunctive effects on organizational innovation.

Finally, we have made a methodological contribution. Most of the ambidexterity research relies on regression analysis (Heavey and Simsek 2017; Lubatkin et al. 2006; Raisch et al. 2009) or case studies (Andriopoulos and Lewis 2009). The application of QCA is seen as a proper method in doing research on complex causation (Ragin 2008) and will offer more insights into exploration-exploitation and ambidexterity research. In addition, QCA lies between qualitative and quantitative methods and, hence, possesses strengths of both. This methodology deepens our understanding of complex interactions between social phenomena and contributes to complexity theory research.

\section{Managerial implications}

In terms of practical implications, firm managers should bear in mind that every factor is in complex combination with other factors. If they want to improve exploration or exploitation, they should jointly consider a number of antecedents, including environmental uncertainty, organizational design (especially unit interdependence), entrepreneurial bricolage and the firm's life cycle stages. Specifically, when dealing with entrepreneurial bricolage and unit interdependence, they should handle their relationship properly in order to achieve exploration or exploitation.

\section{Limitations and future directions}

Like most of other studies, our work is not perfect and has certain flaws, and hence points to directions for future research. First, the antecedents we use here are environmental and organizational factors. In fact, senior management team characteristics (risk aversion, performance feedback and past experience) also matter (Lavie et al. 2010). Future research may add them to configurations. These antecedents may give more insight and interesting combinations for the presence of exploration and exploitation. Second, our sample is mainly small high-tech companies in China, and the sample size is somewhat small though satisfying the requirement of QCA. This limits the 
generalizability of our research results. Future research can collect more diverse samples and enlarge the sample size. Finally, the interaction between antecedents in the real world is much more complex than the QCA can capture. Therefore, applying QCA may only be misleading and conceal the mechanism behind the obvious results. Future research will need to combine QCA with in-depth interviews with founders and high-level managers.

\section{Endnotes}

${ }^{1}$ The difference between fsQCA and mvQCA lies in the type of data they can process. fsQCA is suitable when data values are between 0 and 1 , while mvQCA applies to data values that are integers from 0 to $n$.

${ }^{2}$ By using the 6-point Likert scale, we required the respondents to choose between 3 and 4 ( 3 represents somewhat disagree, while 4 represents somewhat agree), instead of just choosing 3 (the middle point) in the 5-point Likert scale, granting more meaningful qualitative distinctions to variables.

${ }^{3}$ Configurations that do not empirically occur are called "logical remainders."

${ }^{4}$ In order to present the table in a neat and clean manner, we do not display variables according the sequence in the theory development section. We believe that the sequence problem will not influence our interpretation of the configurations but just make the table more readable.

\section{Acknowledgements}

The authors appreciate the financial support from the Major Basic Research Project of Scientific Research Program at Renmin University of China (13XNL004).

Funding

This work is supported by the Major Basic Research Project of Scientific Research Program at the Renmin University of China (Project No: 13XNL004; Project Name: Varieties and Development Paths of Group Control Modes in Enterprises). Renmin University of China provides necessary finical supports during the design of the study and collection, analysis, and interpretation of data and in writing the manuscript.

Availability of data and materials

Please contact author for data requests. Data were collected from small firm founders and high-level managers in China. For data requests, please contact us and we will discuss with the respondents to see if they want to make data public.

\section{Authors' contributions}

$L L$ conceived of the study, and participated in its design and coordination and helped to draft the manuscript. FB helped to draft the manuscript and offered valuable suggestions. XK helped to contact the respondents, carried out the study and helped to draft the manuscript. All authors read and approved the final manuscript.

\section{Ethics approval and consent to participate}

All the data are collected from entrepreneurs and high-level managers under their consent and data collection is strict with ethical standards.

\section{Consent for publication}

We clearly tell the participants that we will use data collected from them to carry out our research. Participants know and consent to publish.

Competing interests

The authors declare that they have no competing interests.

\section{Publisher's Note}

Springer Nature remains neutral with regard to jurisdictional claims in published maps and institutional affiliations.

\section{Author details}

${ }^{1}$ Renmin Business School, Renmin University of China, Beijing 100872, China. ${ }^{2}$ School of Social Sciences, Tsinghua University, Beijing 100084, China. 
Received: 12 June 2018 Accepted: 3 January 2019

Published online: 30 January 2019

\section{References}

Andriopoulos, C., \& Lewis, M. W. (2009). Exploitation-exploration tensions and organizational ambidexterity: Managing paradoxes of innovation. Organization Science, 20(4), 696-717.

Asif, M. (2017). Exploring the antecedents of ambidexterity: A taxonomic approach. Management Decision, 55(7), $1489-1505$.

Baker, T., \& Nelson, R. E. (2005). Creating something from nothing: Resource construction through entrepreneurial bricolage. Administrative Science Quarterly, 50(3), 329-366.

Barnett, W. P. (1997). The dynamics of competitive intensity. Administrative Science Quarterly, 42(1), 128-160.

Benner, M. J., \& Tushman, M. L. (2003). Exploitation, exploration, and process management: The productivity dilemma revisited. Academy of Management Review, 28(2), 238-256.

Berg-Schlosser, D., De Meur, G., Ragin, C., \& Rihoux, B. (2009). Qualitative comparative analysis (QCA) as an approach.

Burns, L. R., \& Wholey, D. R. (1993). Adoption and abandonment of matrix management programs: Effects of organizational characteristics and interorganizational networks. Academy of Management Journal, 36(1), 106-138.

Campbell, J. T., Sirmon, D. G., \& Schijven, M. (2016). Fuzzy logic and the market: A configurational approach to investor perceptions of acquisition announcements. Academy of Management Journal, 59(1). https://doi.org/10.5465/amj.2013.0663.

Cao, Q., Gedajlovic, E., \& Zhang, H. (2009). Unpacking organizational ambidexterity: Dimensions, contingencies, and synergistic effects. Organization Science, 20(4), 781-796.

Chan, H. K., Yee, R. W., Dai, J., \& Lim, M. K. (2016). The moderating effect of environmental dynamism on green product innovation and performance. International Journal of Production Economics, 181, 384-391.

Chandler, A. D. (1962). Strategy and structure: Chapters in the history of the American enterprise. Cambridge: Massachusetts Institute of Technology Cambridge.

Chang, Y. C., Yang, P. Y., \& Chen, M. H. (2009). The determinants of academic research commercial performance: Towards an organizational ambidexterity perspective. Research Policy, 38(6), 936-946.

Chen, M. J., \& Hambrick, D. C. (1995). Speed, stealth, and selective attack: How small firms differ from large firms in competitive behavior. Academy of Management Journal, 38(2), 453-482.

Chu, Z., Xu, J., Lai, F., \& Collins, B. J. (2018). Institutional theory and environmental pressures: The moderating effect of market uncertainty on innovation and firm performance. IEEE Transactions on Engineering Management, 65(3), $392-403$.

Coad, A., Segarra, A., \& Teruel, M. (2016). Innovation and firm growth: Does firm age play a role? Research Policy, 45(2), $387-400$.

Craig, J., \& Dibrell, C. (2006). The natural environment, innovation, and firm performance: A comparative study. Family Business Review, 19(4), 275-288.

Cronqvist, L. (2005). Introduction to multi-value qualitative comparative analysis (MVQCA). COMPASSS didactics paper, (2005/4).

Daft, R. L., \& Weick, K. E. (1984). Toward a model of organizations as interpretation systems. Academy of Management Review, 9(2), 284-295.

De Carolis, D. M., \& Saparito, P. (2006). Social capital, cognition, and entrepreneurial opportunities: A theoretical framework. Entrepreneurship Theory and Practice, 30(1), 41-56.

Dibrell, C., Craig, J., \& Hansen, E. (2011). Natural environment, market orientation, and firm innovativeness: An organizational life cycle perspective. Journal of Small Business Management, 49(3), 467-489.

Dusa, A. (2007). User manual for the QCA(GUI) package in R. Journal of Business Research, 60(5), 576-586.

Emerson, R. M. (1962). Power-dependence relations. American Sociological Review, 27(1), 31-41.

Fiss, P. C. (2007). A set-theoretic approach to organizational configurations. Academy of Management Review, 32(4), 1180-1198.

Fiss, P. C. (2011). Building better causal theories: A fuzzy set approach to typologies in organization research. Academy of Management Journal, 54(2), 393-420.

Gibson, C. B., \& Birkinshaw, J. (2004). The antecedents, consequences and mediating role of organizational ambidexterity. Academy of Management Journal, 47, 209-226.

Govindarajan, V., \& Trimble, C. (2005). Organizational DNA for strategic innovation. California Management Review, 47(3), 47-76.

Greckhamer, T., Misangyi, V. F., Elms, H., \& Lacey, R. (2008). Using qualitative comparative analysis in strategic management research: An examination of combinations of industry, corporate, and business-unit effects. Organizational Research Methods, 11(4), 695-726

Green, K. M., Covin, J. G., \& Slevin, D. P. (2008). Exploring the relationship between strategic reactiveness and entrepreneurial orientation: The role of structure-style fit. Journal of Business Venturing, 23(3), 356-383.

Gresov, C., \& Stephens, C. (1993). The context of interunit influence attempts. Administrative Science Quarterly, 38(2), 252-276.

Guo, H., Su, Z., \& Ahlstrom, D. (2016). Business model innovation: The effects of exploratory orientation, opportunity recognition, and entrepreneurial bricolage in an emerging economy. Asia Pacific Journal of Management, 33(2), 533-549.

He, Z. L., \& Wong, P. K. (2004). Exploration vs. exploitation: An empirical test of the ambidexterity hypothesis. Organization Science, 15(4), 481-494.

Heavey, C., \& Simsek, Z. (2017). Distributed cognition in top management teams and organizational ambidexterity: The influence of transactive memory systems. Journal of Management, 43(3), 919-945.

Hoang, H., \& Rothaermel, F. T. (2010). Leveraging internal and external experience: Exploration, exploitation, and R\&D project performance. Strategic Management Journal, 31(7), 734-758.

Ireland, R. D., Covin, J. G., \& Kuratko, D. F. (2009). Conceptualizing corporate entrepreneurship strategy. Entrepreneurship Theory and Practice, 33(1), 19-46.

Jansen, J., Van den Bosch, F., \& Volberda, H. (2006). Exploratory innovation, exploitative innovation, and performance: Effects of organizational antecedents and environmental moderators. Management Science, 52(11), 1661-1674.

Jansen, J. J., Vera, D., \& Crossan, M. (2009). Strategic leadership for exploration and exploitation: The moderating role of environmental dynamism. The Leadership Quarterly, 20(1), 5-18.

Jawahar, I. M., \& McLaughlin, G. L. (2001). Toward a descriptive stakeholder theory: An organizational life cycle approach. Academy of Management Review, 26(3), 397-414.

Kauppila, O. P. (2010). Creating ambidexterity by integrating and balancing separate interorganizational partnerships. Strategic Organization, 8, 283-312. 
Kazanjian, R. K. (1988). Relation of dominant problems to stages of growth in technology-based new ventures. Academy of Management Journal, 31(2), 257-279.

Koryak, O., Lockett, A., Hayton, J., Nicolaou, N., \& Mole, K. (2018). Disentangling the antecedents of ambidexterity: Exploration and exploitation. Research Policy, 47(2), 413-427.

Lavie, D., Stettner, U., \& Tushman, M. L. (2010). Exploration and exploitation within and across organizations. Academy of Management Annals, 4(1), 109-155.

Lévi-Strauss, C. (1967). The savage mind. Chicago: University of Chicago Press.

Li, P. P. (2012). Toward an integrative framework of indigenous research: The geocentric implications of yin-yang balance. Asia Pacific Journal of Management, 29(4), 849-872.

Lin, Z., Yang, H., \& Demirkan, I. (2007). The performance consequences of ambidexterity in strategic alliance formations: Empirical investigation and computational theorizing. Management Science, 53(10), 1645-1658.

Lubatkin, M., Simsek, Z., Ling, Y., \& Veiga, J. (2006). Ambidexterity and performance in small- to medium-sized firms: The pivotal role of TMT behavioral integration. Journal of Management, 32(5), 1--27.

Luca, D., Ferraris, A., Papa, A., \& Vrontis, D. (2018). The role of external embeddedness and knowledge management as antecedents of ambidexterity and performances in Italian SMEs. Small Business Economics, 1-27.

Mahoney, J. T., \& Michael, S. C. (2005). A subjectivist theory of entrepreneurship. In Handbook of entrepreneurship research (pp. 33-54). Boston: Springer.

March, J. (1991). Exploration and exploitation in organizational learning. Organization Science, 2(1), 71-87.

McCann, J. E., \& Ferry, D. L. (1979). An approach for assessing and managing inter-unit interdependence. Academy of Management Review, 4(1), 113-119.

Meyer, A., Brooks, G., \& Goes, J. (1990). Environmental jolts and industry revolutions: Organizational responses to discontinuous change. Strategic Management Journal, 11(1), 93-110.

Miller, D. (1986). Configurations of strategy and structure: Towards a synthesis. Strategic Management Journal, 7(3), 233-249.

Miller, D. (1987). The structural and environmental correlates of business strategy. Strategic Management Journal, 8(1), 55-76.

Misangyi, V. F., \& Acharya, A. G. (2014). Substitutes or complements? A configurational examination of corporate governance mechanisms. Academy of Management Journal, 57(6), 1681-1705.

Misangyi, V. F., Greckhamer, T., Furnari, S., Fiss, P. C., Crilly, D., \& Aguilera, R. (2017). Embracing causal complexity: The emergence of a neo-configurational perspective. Journal of Management, 43(1), 255-282.

Moorman, C., \& Slotegraaf, R. J. (1999). The contingency value of complementary capabilities in product development. Journal of Marketing Research, 36(2), 239-257.

Mosakowski, E. (2017). Strategic entrepreneurship: Creating a new mindset, Wiley.

Nelson, R. R., \& Winter, S. G. (1982). The Schumpeterian tradeoff revisited. The American Economic Review, 72(1), 114-132.

Nerkar, A. (2003). Old is gold? The value of temporal exploration in the creation of new knowledge. Management Science, 49(2), 211-229.

Nohria, N., \& Gulati, R. (1996). Is slack good or bad for innovation? Academy of Management Journal, 39(5), 1245-1264.

O'Reilly, C. A., \& Tushman, M. L. (2013). Organizational ambidexterity: Past, present, and future. Academy of Management Perspectives, 27(4), 324-338.

Ouchi, W. G. (1977). The relationship between organizational structure and organizational control. Administrative Science Quarterly, 22(1), 95-113.

Penrose, E. T. (1959). The theory of the growth of the firm. New York: Sharpe.

Quinn, R. E., \& Cameron, K. S. (1988). Paradox and transformation: Toward a theory of change in organization and management. New York: Ballinger Publishing Co/Harper and Row Publishers.

Ragin, C. C. (2000). Fuzzy-set social science. Chicago: University of Chicago Press.

Ragin, C. C. (2008). Redesigning social inquiry: Fuzzy sets and beyond. Chicago: University of Chicago Press.

Ragin, C. C. (2014). The comparative method: Moving beyond qualitative and quantitative strategies. Chicago: University of California Press.

Raisch, S., \& Birkinshaw, J. (2008). Organizational ambidexterity: Antecedents, outcomes, and moderators. Journal of Management, 34(3), 375-409.

Raisch, S., Birkinshaw, J., Probst, G., \& Tushman, M. L. (2009). Organizational ambidexterity: Balancing exploitation and exploration for sustained performance. Organization Science, 20(4), 685-695.

Raisch, S., and Zimmermann, A. (2017). A process perspective on the exploration-exploitation paradox. The Oxford Handbook of Organizational Paradox.

Ravishankar, M. N., \& Gurca, A. (2016). A bricolage perspective on technological innovation in emerging markets. IEEE Transactions on Engineering Management, 63(1), 53-66.

Roper, S., \& Tapinos, E. (2016). Taking risks in the face of uncertainty: An exploratory analysis of green innovation. Technological Forecasting and Social Change, 112, 357-363.

Rowley, T. B., Behrens, D., \& Krackhardt, D. (2000). Redundant governance structures:An analysis of structural and relational embeddedness in the steel and semiconductor industries. Strategic Management Journal, 21, 369-386.

Salunke, S., Weerawardena, J., \& McColl-Kennedy, J. R. (2013). Competing through service innovation: The role of bricolage and entrepreneurship in project-oriented firms. Journal of Business Research, 66(8), 1085-1097.

Senik, Z. C., Scott-Ladd, B., Entrekin, L., \& Adham, K. A. (2011). Networking and internationalization of SMEs in emerging economies. Journal of International Entrepreneurship, 9(4), 259-281.

Senyard, J., Baker, T., \& Davidsson, P. (2009). Entrepreneurial bricolage: Towards systematic empirical testing. Frontiers of Entrepreneurship Research, 29(5), 1-15.

Senyard, J., Baker, T., Steffens, P., \& Davidsson, P. (2014). Bricolage as a path to innovativeness for resource-constrained new firms. Journal of Product Innovation Management, 31(2), 211-230.

Siggelkow, N., \& Levinthal, D.A. (2003). Temporarily divide to conquer: Centralized, decentralized, and reintegrated organizational approaches to exploration and adaptation. Organization Science, 14(6), 650-669.

Smith, K. G. Mitchell, T. R., \& Summer, C. E. (1985). Top level management priorities in different stages of the organizational life cycle. Academy of Management Journal, 28(4), 799-820. 
Smith, W. K. (2014). Dynamic decision making: A model of senior leaders managing strategic paradoxes. Academy of Management Journal, 57(6), 1592-1623.

Smith, W. K., \& Lewis, M. W. (2011). Toward a theory of paradox: A dynamic equilibrium model of organizing. Academy of Management Review, 36(2), 381-403.

Smith, W. K., \& Tushman, M. L. (2005). Managing strategic contradictions: A top management model for managing innovation streams. Organization Science, 16(5), 522-536.

Sørensen, J. B., \& Stuart, T. E. (2000). Aging, obsolescence, and organizational innovation. Administrative Science Quarterly, 45(1), 81-112

Stettner, U., \& Lavie, D. (2015). Ambidexterity under scrutiny: Exploration and exploitation via internal organization, alliances, and acquisitions. Strategic Management Journal, 35(13), 1903-1929.

Thompson, J. D. (1967). Organizations in action: Social science bases of administrative theory. Piscataway: Transaction Publishers.

Tsai, W. (2002). Social structure of "coopetition" within a multiunit organization: Coordination, competition, and intraorganizational knowledge sharing. Organization Science, 13(2), 179-190.

Tsai, W., \& Ghoshal, S. (1998). Social capital and value creation: The role of intrafirm networks. Academy of Management Journal, 41(4), 464-476.

Turner, N., Swart, J., \& Maylor, H. (2013). Mechanisms for managing ambidexterity: A review and research agenda. International Journal of Management Reviews, 15(3), 317-332.

Turturea, R., Jansen, J., \& Verheul, I. (2014). The role of bricolage in triggering exploration and exploitation in small and medium-sized enterprises. Frontiers of Entrepreneurship Research, 34(11), 6.

Tushman, M. L., \& Anderson, P. (1986). Technological discontinuities and organizational environments. Administrative Science Quarterly, 31(3), 439-465.

Tushman, M. L., \& O'Reilly, C. A. (2002). Winning through innovation: A practical guide to leading organizational change and renewal. Boston: Harvard University Press.

Tushman, M. L., \& O'Reilly III, C. A. (1996). Ambidextrous organizations: Managing evolutionary and revolutionary change. California Management Review, 38(4), 8-29.

Victor, B., \& Blackburn, R. S. (1987). Interdependence: An alternative conceptualization. Academy of Management Review, 12(3), 486-498.

Wadhwa, A., \& Kotha, S. (2006). Knowledge creation through external venturing: Evidence from the telecommunications equipment manufacturing industry. Academy of Management Journal, 49(4), 819-835.

Witell, L., Gebauer, H., Jaakkola, E., Hammedi, W., Patricio, L., \& Perks, H. (2017). A bricolage perspective on service innovation. Journal of Business Research, 79, 290-298.

Zhang, Y., \& Li, H. (2010). Innovation search of new ventures in a technology cluster: The role of ties with service intermediaries. Strategic Management Journal, 31(1), 88-109.

\section{Submit your manuscript to a SpringerOpen ${ }^{\circ}$ journal and benefit from:}

- Convenient online submission

- Rigorous peer review

- Open access: articles freely available online

High visibility within the field

- Retaining the copyright to your article

Submit your next manuscript at $\boldsymbol{\nabla}$ springeropen.com 